\title{
RESEARCH AND COMMERCIALISATION OF TREATMENT OF FINE ILMENITE WITH SLOn MAGNETIC SEPARATORS
}

\author{
XIONG DA-HE \\ Ganzhou Nonferrous Metallurgy Research Institute, 36 Qingnian Road, \\ Ganzhou 341000, Jiangxi Province, P.R. China
}

(Received 16 September 1999; Accepted 27 September 1999)

The fine ilmenite material finer than $0.045 \mathrm{~mm}$ at the Pang Zhi Hua Ilmenite Processing Plant was discarded for the lack of efficient processing equipment and method. The total recovery of ilmenite in the plant had been only about $17-20 \%$. To increase the ilmenite recovery, numerous laboratory, pilot and commercial tests were conducted in 1995-1996. Finally, a magnetic separation-flotation flowsheet was chosen for the commercial test, in which the fine fraction was fed into $125 \mathrm{~mm}$ diameter cyclones for desliming. The underflow of the cyclones was then fed into the magnetic separation-flotation flowsheet. A SLon1500 vertical ring and pulsating high gradient magnetic separator was applied as a rougher and was followed by flotation as a cleaner. The overall results of the magnetic separationflotation flowsheet in the commercial test were: feed $11.03 \% \mathrm{TiO}_{2}$, concentrate $47.36 \%$ $\mathrm{TiO}_{2}$, recovery $44.79 \% \mathrm{TiO}_{2}$. The flowsheet of the commercial test has been used as a production process since 1997 . The recovery accounted for about $12 \% \mathrm{TiO}_{2}$ of the feed into the ilmenite processing plant.

Keywords: Ilmenite; Magnetic separation; SLon pulsating magnetic separator

\section{INTRODUCTION}

The Pang Zhi Hua Ilmenite Processing Plant is the biggest producer of ilmenite in China. The deposit consists of vanadium, titanium and iron minerals and other gangues. Magnetite is the major iron mineral and vanadium exists in magnetite. Ilmenite is the major titanium mineral. An iron processing plant recovers magnetite and vanadium before the ilmenite processing plant. The tails of the iron processing plant represent the feed into the ilmenite processing plant. 
The previous flowsheet of the ilmenite processing plant was based on classification into $+0.1 \mathrm{~mm}$ (coarse), $0.1-0.045 \mathrm{~mm}$ (middle) and $-0.045 \mathrm{~mm}$ (fine) fractions. The coarse and the middle particle fractions were treated with spirals and electrical separators. The fine fraction was discarded as the final tails for the lack of efficient beneficiation technology. The overall recovery of ilmenite had been only $17-20 \%$ of the feed of the ilmenite processing plant.

The mass of the fine fraction is about $35 \%$ and the $\mathrm{TiO}_{2}$ grade is almost the same as that of the feed to the ilmenite plant. The recovery of ilmenite from the fine particle fraction is thus of great significance for increasing the overall recovery of the ilmenite plant.

\section{MINERALOGICAL ANALYSIS}

Major minerals and their physical properties in the feed into the ilmenite plant are shown in Table I.

\section{THE LABORATORY TESTWORK ON FINE ILMENITE}

\subsection{Laboratory Tests of Magnetic Separation}

Ilmenite is our target mineral to be recovered and the other minerals are considered to be tailings. It can be seen from Table I that magnetic susceptibilities of vanadium-titanium magnetite, ilmenite and pyrite are relatively stronger than the others. But magnetic susceptibility of titaniferous augite is close to that of ilmenite. It is possible to remove plagioclase and part of titaniferous augite by magnetic separation.

The fine particle fraction $(-0.045 \mathrm{~mm})$ of the ilmenite plant feed was used as the feed in our laboratory test. SLon- 100 cyclic pulsating high gradient magnetic separator (SLon-100) was used as a rougher. In the test, the matrix type, the background magnetic induction, pulsating stroke and pulsating frequency were optimized. Typical results of the magnetic separation test are shown in Table II.

Table II shows that with $4 \mathrm{~mm}$ dia. rod matrix in SLon-100 magnetic separation better results can be obtained than with $2 \mathrm{~mm}$ dia. rod matrix 


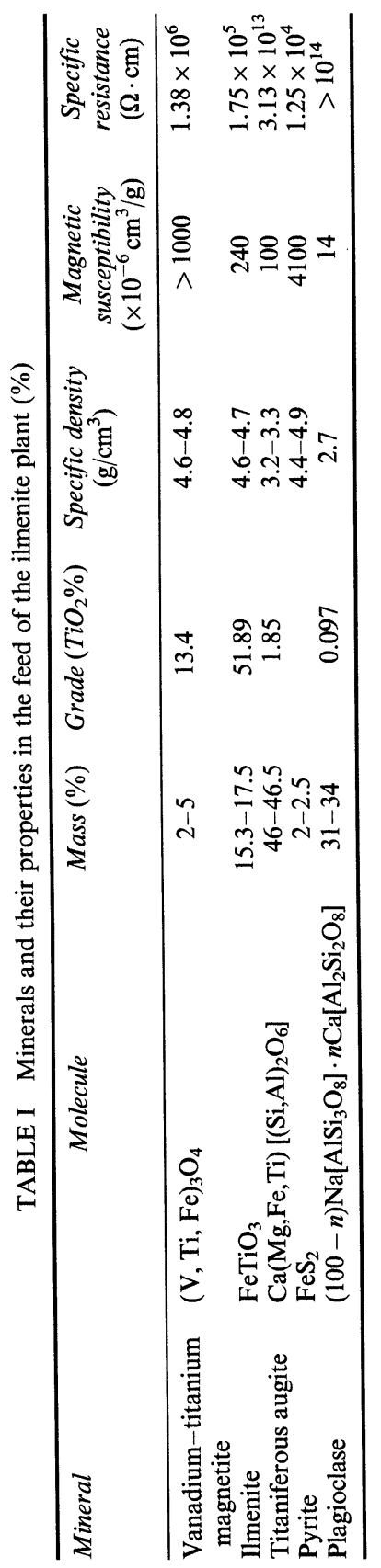




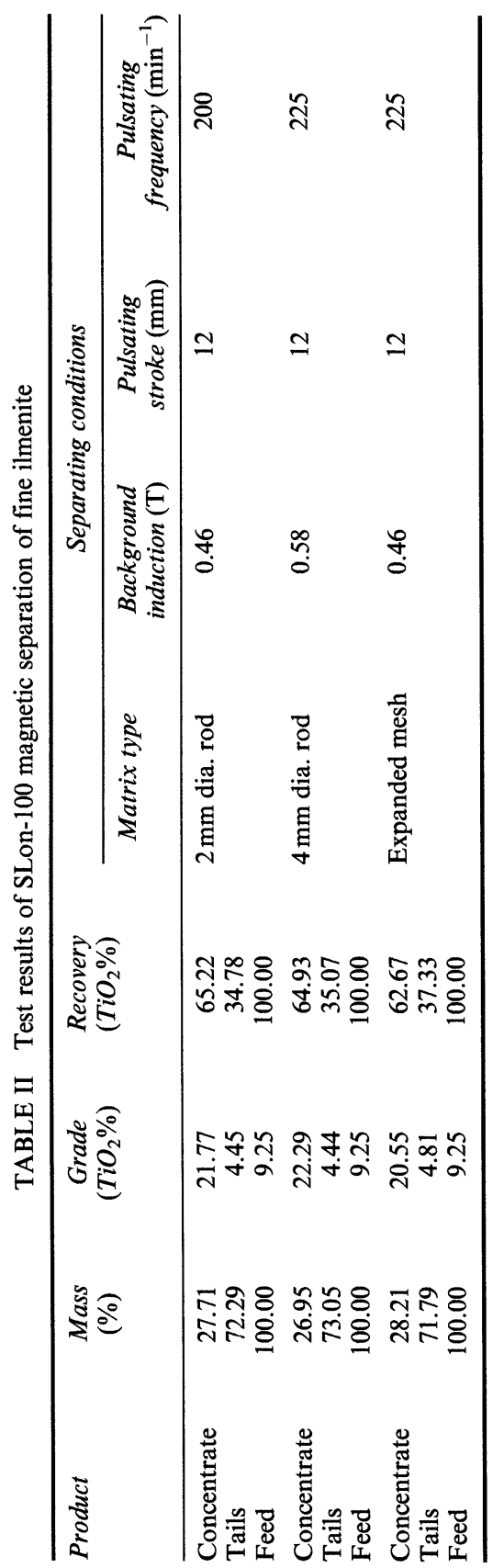


or expanded mesh. When the feed is $9.25 \% \mathrm{TiO}_{2}$ and with $4 \mathrm{~mm} \mathrm{dia}$. rod matrix, the concentrate grade is $22.29 \% \mathrm{TiO}_{2}$, the tails grade is $4.44 \%$ $\mathrm{TiO}_{2}$, recovery in the concentrate is $64.93 \% \mathrm{TiO}_{2}$, the mass of the concentrate is only $26.95 \%$ and the mass of the tails is $73.05 \%$. The importance of magnetic separation is that it can discard about $73 \%$ by mass of the low-grade tails and only about $27 \%$ by mass of the concentrate enters into next cleaning stage. For example, if flotation is used for the cleaning, a lot of flotation reagents can be saved.

\subsection{Laboratory Tests with Flotation as a Cleaning Stage}

In the laboratory flotation tests, several reagents as collectors were tested and the flowsheet was optimized. Typical results are shown in Table III.

The Table shows that the grade of the ilmenite concentrate can be upgraded to about $47 \% \mathrm{TiO}_{2}$ by flotation. Recovery of $\mathrm{TiO}_{2}$ in the flotation stage can reach about $60 \%$ in the open circuit or about $85 \%$ in the closed circuit.

\subsection{Summary of the Laboratory Tests}

Table IV shows the overall results of magnetic and flotation separation in laboratory tests. With SLon-100 magnetic separation as a rougher and flotation as a cleaner, we can get the final concentrate with $47.10 \%$ $\mathrm{TiO}_{2}$ grade and $55.47 \%$ recovery in the closed flotation circuit or $46.87 \% \mathrm{TiO}_{2}$ grade and $39.12 \%$ recovery in the open flotation circuit.

TABLE III Results of the laboratory test of flotation in the cleaning stage

\begin{tabular}{lrcrc}
\hline Product & $\begin{array}{c}\text { Mass } \\
(\%)\end{array}$ & $\begin{array}{c}\text { Grade } \\
\left(\mathrm{TiO}_{2} \%\right)\end{array}$ & $\begin{array}{c}\text { Recovery } \\
\left(\mathrm{TiO}_{2} \%\right)\end{array}$ & $\begin{array}{c}\text { Flotation } \\
\text { flowsheet }\end{array}$ \\
\hline Concentrate & 40.43 & 47.10 & 85.44 & One roughing, one cleaning, \\
Tails & 59.57 & 5.45 & 14.56 & one scavenging (closed circuit) \\
Feed & 100.00 & 22.29 & 100.00 & \\
Concentrate & 28.65 & 46.87 & 60.24 & One roughing, one cleaning, \\
Tails & 71.35 & 12.42 & 39.76 & one scavenging (open circuit) \\
Feed & 100.00 & 22.29 & 100.00 & \\
Concentrate & 27.21 & 47.54 & 58.04 & One roughing, one cleaning, \\
Tails & 72.79 & 12.85 & 41.96 & one scavenging (open circuit) \\
Feed & 100.00 & 22.29 & 100.00 & \\
\hline
\end{tabular}


TABLE IV Summary of the results of the laboratory tests of magnetic and flotation separation

\begin{tabular}{lrrrr}
\hline Product & $\begin{array}{c}\text { Mass } \\
(\%)\end{array}$ & $\begin{array}{c}\text { Grade } \\
\left(\mathrm{TiO}_{2} \%\right)\end{array}$ & $\begin{array}{c}\text { Recovery } \\
\left(\mathrm{TiO}_{2} \%\right)\end{array}$ & Flotation flowsheet \\
\hline Final concentrate & 10.90 & 47.10 & 55.47 & SLon-100 roughing, \\
Total tails & 89.10 & 4.62 & 44.52 & flotation cleaning (closed circuit) \\
SLon-100 feed & 100.00 & 9.25 & 100.00 & \\
Final concentrate & 7.22 & 46.87 & 39.12 & SLon-100 roughing, \\
Total tails & 92.28 & 6.10 & 60.88 & flotation cleaning (open circuit) \\
SLon-100 feed & 100.00 & 9.25 & 100.00 & \\
\hline
\end{tabular}

The laboratory tests-scale showed the direction for subsequent pilot and commercial tests.

\subsection{Pilot-Plant Tests on Fine Ilmenite}

In 1995, SLon-1000 vertical ring and pulsating high gradient magnetic separator [1] was moved to Pang Zhi Hua Ilmenite Procesing Plant for pilot-plant tests to recover ilmenite from the discarded $-0.045 \mathrm{~mm}$ ilmenite slime. SLon-1000 was installed in the production flowsheet and a slurry stream of $-0.045 \mathrm{~mm}$ ilmenite slime was used as its feed. The magnetic product (the rougher concentrate) was used as the flotation feed in the cleaning stage. The flowsheet of the pilot test is shown in Fig. 1.

In the pilot-plant tests technical parameters were first optimized. Then SLon-1000 ran continuously for $72 \mathrm{~h}$ to get more reliable results. As is shown in Fig. 1, SLon- 1000 removes about $75 \%$ by mass of the low-grade tails, and most of the slimes $(-10 \mu \mathrm{m}$ fraction) which are harmful to the flotation reaction, reported into the tails. Only about $25 \%$ of the mass enters the flotation cleaning stage.

The overall results showed that a good ilmenite concentrate containing $47.60 \% \mathrm{TiO}_{2}$ with the total recovery of $44.20 \% \mathrm{TiO}_{2}$ can be obtained.

\section{THE COMMERCIAL TESTS}

Based on the results of the pilot test a commercial test was carried out in 1996. SLon-1500 vertical ring and pulsating high gradient magnetic 


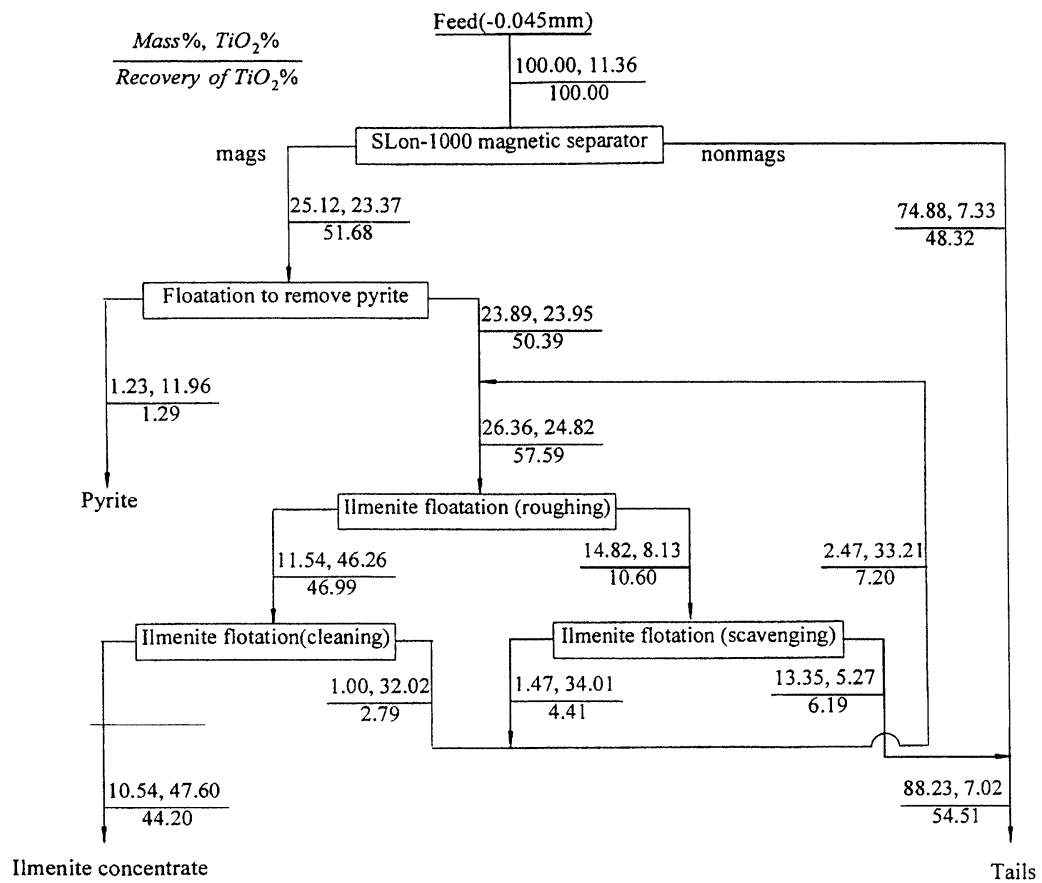

FIGURE 1 The flowsheet of the pilot-plant test of magnetic separation and flotation of the $-0.045 \mathrm{~mm}$ ilmenite slime.

separator was installed in the production flowsheet as shown in Fig. 2. In order to increase the throughput of SLon-1500, $125 \mathrm{~mm}$ diameter cyclones were used to dewater and deslime the $-0.01 \mathrm{~mm}$ slime fraction. The operational results of the cyclones, of SLon-1500 and of flotation are shown in Tables V-VII respectively.

Table $\mathrm{V}$ shows that the cyclone operation is important because the solids concentration in the feed is only $5.42 \%$. The solids concentration of the cyclone underflow is $28.32 \%$. Most water and $-0.01 \mathrm{~mm}$ slimes report into the cyclone overflow. This creates a much better condition for the SLon-1500 operation. As shown in Table VI, the capacity of SLon- 1500 reaches $25.25 \mathrm{t} / \mathrm{h}$ with $76.24 \% \mathrm{TiO}_{2}$ operational recovery. Figure 2 shows that the combined $\mathrm{TiO}_{2}$ recovery of the cyclone and SLon- 1500 is $50.51 \%$, almost the same compared with the pilot test shown in Fig. 1. 


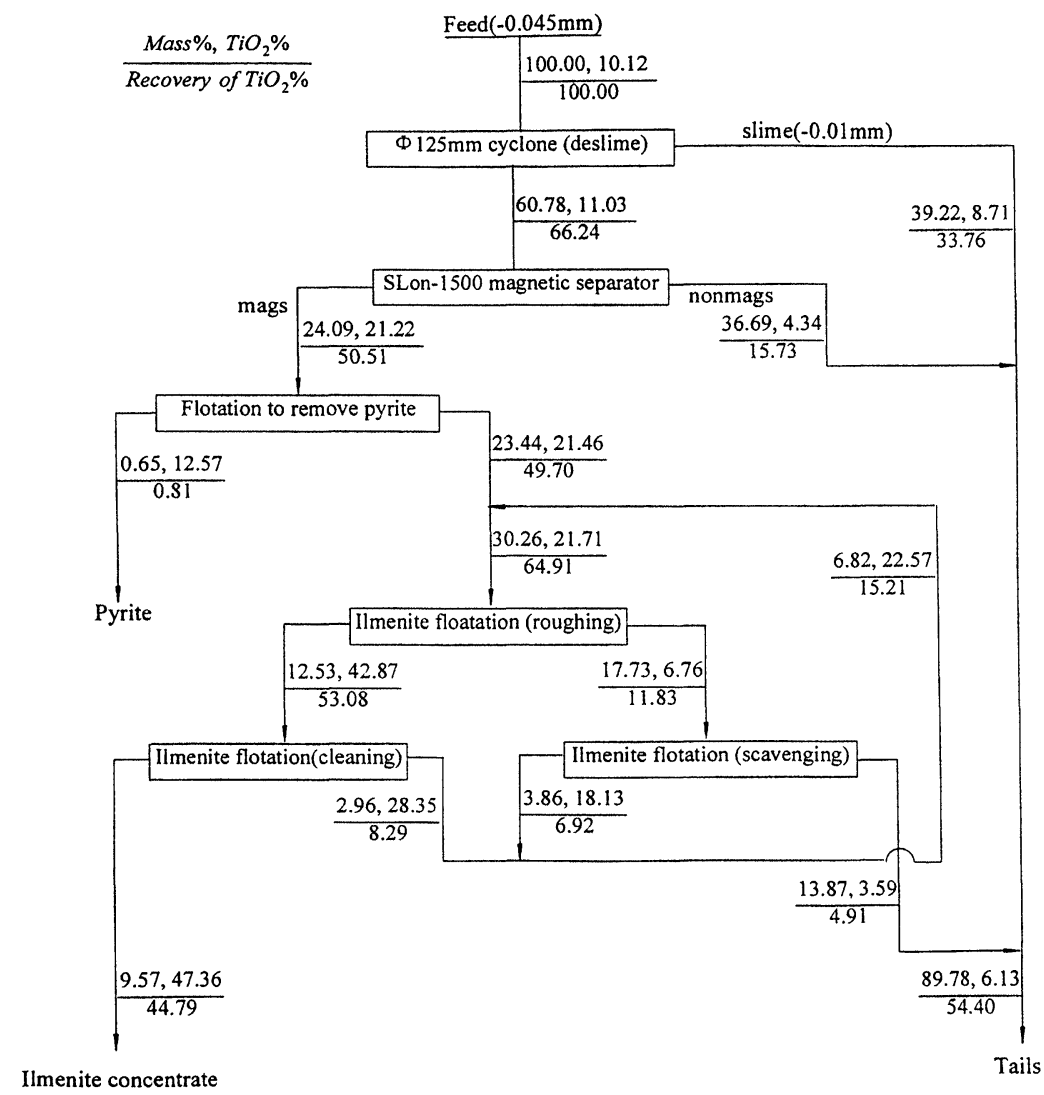

FIGURE 2 The flowsheet of the commercial test of magnetic separation and flotation of the $-0.045 \mathrm{~mm}$ ilmenite fraction.

TABLE V The operational results of $125 \mathrm{~mm}$ diameter cyclones (\%)

\begin{tabular}{|c|c|c|c|c|c|c|c|c|}
\hline \multicolumn{3}{|c|}{ Feed } & \multicolumn{3}{|c|}{ Under flow product } & \multicolumn{3}{|c|}{ Overflow product } \\
\hline $\begin{array}{l}\text { Solid } \\
\text { density }\end{array}$ & $\mathrm{TiO}_{2}$ & $\begin{array}{c}\mathrm{TiO}_{2} \\
\text { distribution }\end{array}$ & $\begin{array}{c}\text { Solid } \\
\text { density }\end{array}$ & $\mathrm{TiO}_{2}$ & $\begin{array}{c}\mathrm{TiO}_{2} \\
\text { distribution }\end{array}$ & $\begin{array}{c}\text { Solid } \\
\text { density }\end{array}$ & $\mathrm{TiO}_{2}$ & $\begin{array}{c}\mathrm{TiO}_{2} \\
\text { distribution }\end{array}$ \\
\hline 5.42 & 10.12 & 100.00 & 28.32 & 11.03 & 66.24 & 2.94 & 8.71 & 33.76 \\
\hline
\end{tabular}

The operation of the cyclone and SLon-1500 created very good conditions for the flotation stage. The first two operations discarded $75.91 \%$ of mass and most of the $-0.01 \mathrm{~mm}$ slimes into the tails. Only $24.09 \%$ of mass of the magnetic concentrate enters into the flotation cleaning stage. As shown in Table VII, the flotation results are very 
TABLE VI The average operational results of SLon-1500 (\%)

\begin{tabular}{|c|c|c|c|c|c|c|c|c|}
\hline \multicolumn{3}{|c|}{ Feed } & \multicolumn{3}{|c|}{ Concentrate } & \multicolumn{3}{|c|}{ Tails } \\
\hline $\mathrm{t} / \mathrm{h}$ & $-0.045 \mathrm{~mm}$ & $\underset{\text { grade }}{\mathrm{TiO}_{2}}$ & Mass & $\begin{array}{c}\mathrm{TiO}_{2} \\
\text { grade }\end{array}$ & $\begin{array}{c}\mathrm{TiO}_{2} \\
\text { recovery }\end{array}$ & Mass & $\begin{array}{l}\mathrm{TiO}_{2} \\
\text { grade }\end{array}$ & $\begin{array}{c}\mathrm{TiO}_{2} \\
\text { distribution }\end{array}$ \\
\hline 25.25 & 75 & 11.03 & 39.63 & 21.22 & 76.24 & 60.37 & 4.34 & 23.76 \\
\hline
\end{tabular}

TABLE VII The average operational results of flotation (\%)

\begin{tabular}{lrcc}
\hline Product & Mass & $\mathrm{TiO}_{2}$ grade & $\mathrm{TiO}_{2}$ distribution \\
\hline Pyrite & 2.70 & 12.57 & 1.60 \\
Ilmenite concentrate & 39.73 & 47.36 & 88.68 \\
Tails & 57.57 & 3.59 & 9.72 \\
Feed (SLon-1500 Mags) & 100.00 & 21.22 & 100.00 \\
\hline
\end{tabular}

good. The final grade of ilmenite concentrate reaches $47.36 \% \mathrm{TiO}_{2}$ and the flotation recovery is $88.68 \% \mathrm{TiO}_{2}$. The overall ilmenite recovery of the full flowsheet is $44.79 \% \mathrm{TiO}_{2}$.

\section{THE PRODUCTION-SCALE APPLICATION}

The commercial test shown in Fig. 2 was completed at the end of 1997, and the flowsheet was implemented on production scale. In 1998, about $10000 \mathrm{t}$ of $>47 \% \mathrm{TiO}_{2}$ ilmenite concentrate was recovered from the $-0.045 \mathrm{~mm}$ fine fraction. After more than a one year-long production practice, it was demonstrated that the SLon-1500 VPHGMS magnetic separator works very reliably. In 1999, the production scale of the $-0.045 \mathrm{~mm}$ fine fraction is expected to reach $15000-20000 \mathrm{t}$ of the ilmenite concentrate as the flowsheet becomes more optimized.

\section{CONCLUSIONS}

A magnetic separation-flotation flowsheet is applied to the recovery of the $-0.045 \mathrm{~mm}$ fine ilmenite minerals from the previous tails in the Pang Zhi Hua Ilmenite Processing Plant. SLon-1500 vertical ring and pulsating high gradient magnetic separator is used in the roughing stage. It is a key equipment for the flotation cleaning stage. The overall flowsheet is relatively simple and reliable. It has been put into production 
by the end of 1997 . The overall results of the flowsheet are as follows: feed grade $11 \% \mathrm{TiO}_{2}$, ilmenite concentrate grade $\geq 47 \% \mathrm{TiO}_{2}$ and $\mathrm{TiO}_{2}$ recovery $44 \%$. Approximately $10000-20000 \mathrm{t}$ of such ilmenite concentrate can be recovered from the previously abandoned tails. It is a significant technological innovation in the history of the Pang Zhi Hua Ilmenite Processing Plant.

\section{Reference}

[1] Xiong, Da-He. New development of the SLon vertical ring pulsation HGMS separator. Magn. Electr. Sep. 5 (1994), 211. 